\title{
NADPH: Quinone oxidoreductase 1 (NQ01609C>T) Polymorphism and Gastric Cancer Risk: A Meta-Analysis
}

\section{Manzoor Ahmad Malik ${ }^{1}$, Haq $\mathbf{S}^{1}$, Yetoo DM ${ }^{2}$, Baba RA ${ }^{1}$, Nissar $\mathbf{S}^{1}$, Gull $\mathbf{A}^{1}$, Malik $\mathbf{S A}^{2}$ and Shah $Z A^{1,2^{*}}$}

${ }^{1}$ Cancer Diagnostic and Research Centre, Department of Immunology and Molecular Medicine, Sher-I-Kashmir Institute of Medical Sciences (SKIMS), Soura, Srinagar, Kashmir-190011, J\&K, India

${ }^{2}$ Department of Immunology and Molecular Medicine, Sher-I-Kashmir Institute of Medical Sciences (SKIMS), Soura, Srinagar, Kashmir-190011, J\&K, India

"Corresponding author: Shah ZA, Department of Immunology and Molecular Medicine, Sher-I-Kashmir Institute of Medical Sciences, Soura, Srinagar, Kashmir-190011, J\&K, India, Tel: +91-9419415278; Email: zaffaramin@gmail.com

Received date: December 31, 2015; Accepted date: January 22, 2016; Published date: January 25, 2016

Copyright: (C) 2016, Malik MA, et al. This is an open-access article distributed under the terms of the Creative Commons Attribution License, which permits unrestricted use, distribution, and reproduction in any medium, provided the original author and source are credited.

\begin{abstract}
Evidence is increasingly emerging about multiple roles for the NAD (P) H quinine oxidoreductase 1 (NQO1) enzyme in gastric cancer (GC). The NQO1609C >T (Pro187Ser) null polymorphism of the NQO1 gene contributes significantly to the variation in enzymatic activity across different populations. NQO1609C $>$ T polymorphism was thoroughly investigated with respect to gastric cancer susceptibility. The results were inconsistent partly due to low sample sizes. The aim of the present work was to perform a meta-analysis to assess association for gastric cancer. Present meta-analysis involved eligible studies including 722 cases and 853 controls. Present metaanalysis found a statistically significant association between the variant $T$ allele and overall cancer risk in the worldwide population (for the TT vs CC; co-dominant model, OR=1.568; 95\% Cl=1.096-2.244; $\mathrm{P}=0.014$ ). At allele level, NQO1609C $>\mathrm{T}$ polymorphism was significantly correlated with increased GC risk $(\mathrm{OR}=1.302 ; 95 \% \mathrm{Cl}=1.111-1.525 ; \mathrm{P}=0.001)$. In subgroup analysis positive association was also found for gastric cancer in recessive (OR=1.456; $95 \% \mathrm{Cl}=1.050-2.020 ; \mathrm{P}=0.024)$ model. Stratified analysis revealed that this association was largely attributed to the Assian ethnicity (for the TT vs CC model, $\mathrm{OR}=1.227 ; 95 \% \mathrm{Cl}=1.022-1.473 ; \mathrm{P}=0.028$ ). Present results indicate that the $609 \mathrm{C}>\mathrm{T}$ polymorphism of the NQO1 gene is an important genetic risk factor in gastric cancer.
\end{abstract}

Keywords: NQO1; 609C>T; Meta-analysis; Gastric cancer

\section{Introduction}

Cancer is a leading cause of death worldwide. It is estimated that the burden of cancer will increase up to 22.2 million new cases diagnosed annually worldwide by 2030 , which represents an increase by $75 \%$ compared with statistics of 2008 [1] Among human cancers, gastric carcinogenesis appears to be a complex multistep processes with multifunctional etiologies, where environmental, geographical, and genetic factors have been attributed to play major roles in causation of cancers. Gastric cancer (GC) has diverse incidences, patterns, and risk factors (like tobacco, alcohol, dietary pattern, sex, family history and Helicobacter pylori infection) [2].

Most of the carcinogens generally undergo bioactivation and inactivation by phase I and phase II enzymes. Quinone oxidoreductases $(\mathrm{NAD}(\mathrm{P}) \mathrm{H}$ : quinone oxidoreductase 1 (coded by NQO1) is phase II cytosolic enzymes that catalyze metabolism of quinones. NQO1 is ubiquitously expressed in all tissue types and induced along with a battery of defensive genes in response to stresses including xenobiotics, antioxidants, oxidants, heavy metals, UV light, and ionizing radiations [3]. The coordinated induction of genes for these enzymes provides necessary protection for cells against free radical damage, oxidative stress, and neoplasia.

The NQO1 gene is located on chromosome 16q22.1. A nonsynonymous SNP has been described by Traver et al., at nucleotide position 609 (rs2070999) [4]. The variant is a C-to-T transition and results in a proline to serine amino acid substitution at codon 187 in the protein. The variant allele results in reduced enzymatic activity according to in vitro studies $[5,6]$. Compared with the wild type (CC), the homozygous variant has only $2 \%$ to $4 \%$ of the quinone reductase activity, whereas the heterozygote variant has a 3 -fold decrease in enzyme activity [7]. The Pro187Ser polymorphism has been linked to benzene toxicity [8], therefore it has also been hypothesized to affect cancer susceptibility by modifying the internal exposure to bioactivated carcinogens. A wide variation of the allele frequency has been observed across ethnic groups. The homozygous variant genotype is as rare as $2 \%$ in white populations but as frequent as $20 \%$ in Asian populations [9]. Also, there are several epidemiological studies reporting association of NQO1 $609 \mathrm{C}>\mathrm{T}$ polymorphism with GC [10-13].

Large number of studies investigated the role of NQO1 609C>T polymorphism and the susceptibility of gastric cancer. However, the results were inconsistent rather than conclusive, possibly due to the small sample size in the majority of studies. Therefore, a meta-analysis of these studies was undertaken to investigate the association of the NQO1609C $>$ T polymorphism with susceptibility to gastric cancer in co-dominant, recessive and allele level. In addition, present study analyzed available data to explore any role of ethnicity on the association of NQO1609C $>\mathrm{T}$ polymorphism in gastric cancer risk.

\section{Materials and Methods}

\section{Identification and eligibility of relevant studies}

To identify all articles that examined the association of NQO1 $609 \mathrm{C}>\mathrm{T}$ polymorphism with GC, literature search was conducted in the Pubmed, EMBASE, Cochrane, google and dogpile, and CBM 
database, up to December 2015 using the following terms and keywords: "NQO1", "Quinone oxidoreductases (NAD $(\mathrm{P}) \mathrm{H}$ : quinone oxidoreductase 1", "polymorphism" and "gastric cancer". Additional studies were identified by a manual search from other sources (e.g., Web of Knowledge), references of original studies or review articles on this topic.

\section{Inclusion and exclusion criteria}

To minimize heterogeneity and facilitate the interpretation of results, studies included in the current meta-analysis had to meet all the following criteria: (1) evaluation of the NQO1609C > T and GC risk, (2) use of a case control design, (3) recruitment of confirmed GC patients and disease-free controls, (4) have an available genotype frequency, and (5) an unrelated case-control study, if studies had partly overlapped subjects, only the one with a larger sample size was selected, (6) sufficient published data for estimating an odds ratio (OR) with 95\% confidence interval (CI), and (7) papers published in English.

The major reasons for exclusion of studies were (1) overlapping data (2) case-only studies, (3) all three genotype frequency missing, (4) family based studies, (5) review articles, (6) age and gender unmatched studies, (7) ethnicity unmatched studies, (8) the studies which were not in HWE and (9) papers published in other languages other than English.

\section{Data extraction}

All investigators independently assessed the articles for inclusion/ exclusion and extracted data, and reached a consensus on all of the items. For each study, the following information was extracted: name of the first author; publication year; ethnicity (country); sample size (numbers of cases and controls); gene polymorphisms investigated; types of disease; sources of samples; genotyping methods; and the minor allele frequency in the controls with the Hardy-Weinberg Equilibrium (HWE) p-value, respectively.

\section{Statistical analysis}

The association between NQO1609C $>\mathrm{T}$ polymorphism and gastric cancer was estimated by calculating pooled odd ratios (ORs) and $95 \%$ CIs. The significance of the pooled OR was determined by $\mathrm{Z}$ test $(\mathrm{P}<0.05$ was considered statistically significant). The risk of NQO1609C $>$ T TT genotype on gastric cancer was evaluated by comparing with their reference wild type homozygote and then evaluated the risks of $(\mathrm{CT}+\mathrm{TT}$ vs $\mathrm{CC})$ and $(\mathrm{CC}+\mathrm{CT}$ vs $\mathrm{TT})$ on gastric cancer, assuming dominant and recessive effects of the variant TT allele, respectively. A random-effects or fixed-effects model was used to calculate pooled effect estimates in the presence $(\mathrm{P}<0.10)$ or absence $(\mathrm{P}>0.10)$ of heterogeneity. Publication bias was detected for the overall pooled analysis of NQO1609C $>$ T TT genotypes, and recessive model. Additionally funnel plot was drawn, symmetry of the funnel plot means a potential publication bias. For the one-way sensitivity analysis, one single study was excluded each time, and the new pooled results could reflect the influence of that deleted study to the overall summary OR. All Meta-analysis tests were performed through comprehensive Meta-analysis version 2.0.

\section{Results}

Ten studies were preliminarily retrieved. Six studies were excluded after reading the titles and abstracts (Figure 1).

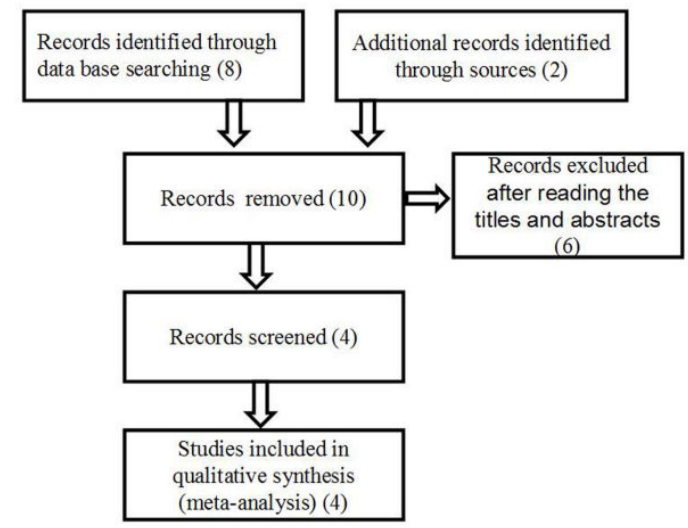

Figure 1: Flow chat of study selection.

According to inclusion and exclusion standards, four studies were finally included [10-13], the publication years of the literatures was between January 2000 and December 2015. The general features of the researches were included (Table 1).

\begin{tabular}{|l|l|l|l|l|l|l|l|l|l|l|l|}
\hline Reference & Author & Year & Country & Ethnicity & $\begin{array}{l}\text { Study } \\
\text { Design }\end{array}$ & $\begin{array}{l}\text { Genotyping } \\
\text { Method }\end{array}$ & Cases & Controls & HW E & Sample & Pubmed ID \\
\hline 10 & $\begin{array}{l}\text { Hamajima et } \\
\text { al. }\end{array}$ & 2002 & Japan & Asian & HB & PCR-RFLP & 143 & 241 & 0.25 & Blood & PMID: 12018106 \\
\hline 11 & Zhang et al. & 2003 & China & Asian & HB & PCR-RFLP & 124 & 165 & 0.39 & Blood & PMID: 12854127 \\
\hline 12 & Sarbia et al. & 2003 & Germany & Eropean & HB & PCR-RFLP & 320 & 252 & 0.60 & Blood & PMID: 14506737 \\
\hline 13 & Malik et al. & 2011 & India & Asian & HB & PCR-RFLP & 135 & 195 & 0.30 & Blood & PMID: 22736108 \\
\hline
\end{tabular}

Table 1: Characteristics of studies included in the NQO1609C $>$ T meta-analysis.

\section{Potential publication bias and sensitivity analysis}

The influence of TT genotype at $609 \mathrm{C}>\mathrm{T}$ locus on NQO1 was taken as the analysis index and inverted funnel plot was drawn. Due to the small amount of the included research and unobvious distribution trends, the inverted funnel plot showed trend symmetry, indicating that the publication bias was not big (Figure 2). 
Citation: Malik MA, Haq S, Yetoo DM, Malik SA, Shah ZA (2016) NADPH: Quinone oxidoreductase 1 (NQO1609C>T) Polymorphism and Gastric

Page 3 of 5

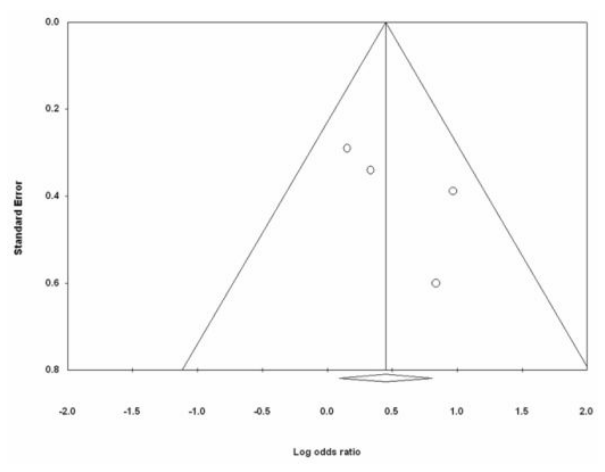

Figure 2: Funnel plots showed symmetric distribution. Log OR is plotted against the standard error of $\log$ OR for studies on NQO1609C $>$ T.

\section{Meta-analysis database}

In an attempt to obtain a common estimate of the NQO1609C $>$ T polymorphisms effect on risk for GC and provide compelling evidence for association, a meta-analysis was performed combining all available genotype and allele frequency data from published studies. The detailed characteristics of each study included in the meta-analysis are presented in Table 1 , and the NQO1609C $>\mathrm{T}$ polymorphism genotype distributions from each study are presented in Table 2 .

\begin{tabular}{|c|c|c|c|c|c|c|c|c|c|c|c|c|c|c|c|c|c|c|c|c|}
\hline \multirow[t]{2}{*}{ Reference } & \multirow[t]{2}{*}{ Author } & \multirow[t]{2}{*}{ Year } & \multicolumn{3}{|c|}{ Cases } & \multicolumn{3}{|c|}{ Controls } & \multicolumn{2}{|c|}{$\begin{array}{l}\text { Cases } \\
\text { (Allele) }\end{array}$} & \multicolumn{2}{|c|}{$\begin{array}{l}\text { Controls } \\
\text { (Allele) }\end{array}$} & \multicolumn{2}{|c|}{$\begin{array}{l}\text { Cases } \\
\text { dominant } \\
\text { model }\end{array}$} & \multicolumn{2}{|c|}{$\begin{array}{l}\text { Controls } \\
\text { dominant } \\
\text { model }\end{array}$} & \multicolumn{2}{|c|}{$\begin{array}{l}\text { Cases } \\
\text { Recessive } \\
\text { model }\end{array}$} & \multicolumn{2}{|c|}{$\begin{array}{l}\text { Controls } \\
\text { Recessive } \\
\text { model }\end{array}$} \\
\hline & & & CC & CT & TT & $\mathrm{CC}$ & СT & TT & $\mathrm{CC}$ & TT & $\mathrm{CC}$ & TT & $\mathrm{CC}$ & $\mathrm{CT}+\mathrm{TT}$ & $\mathrm{CC}$ & $\mathrm{CT}+\mathrm{TT}$ & $\mathrm{CC}+\mathrm{CT}$ & TT & $\mathrm{CC}+\mathrm{CT}$ & TT \\
\hline 10 & $\begin{array}{l}\text { Hamajima } \\
\text { et al. }\end{array}$ & 2002 & 48 & 71 & 24 & 154 & 179 & 66 & 167 & 119 & 487 & 311 & 48 & 95 & 154 & 245 & 119 & 24 & 333 & 66 \\
\hline 11 & Zhang et al. & 2003 & 40 & 55 & 29 & 52 & 86 & 27 & 135 & 113 & 190 & 140 & 40 & 84 & 52 & 311 & 95 & 29 & 138 & 27 \\
\hline 12 & Sarbia et. al & 2003 & 200 & 10 & 10 & 185 & 63 & 4 & 510 & 130 & 433 & 71 & 200 & 120 & 185 & 67 & 310 & 10 & 248 & 4 \\
\hline 13 & Malik et al. & 2012 & 51 & 39 & 18 & 112 & 68 & 15 & 141 & 75 & 292 & 98 & 51 & 57 & 112 & 83 & 90 & 18 & 180 & 15 \\
\hline
\end{tabular}

Table 2: NQO1609C $>$ T polymorphism genotype distribution of each study included in the meta-analysis.

By pooling all the studies and NQO1609C $>\mathrm{T}$ polymorphism was associated with GC risk in co-dominant model (OR=1.568; 95\%CI=1.096-2.244; $\mathrm{P}=0.014$ ) (Figure 3).

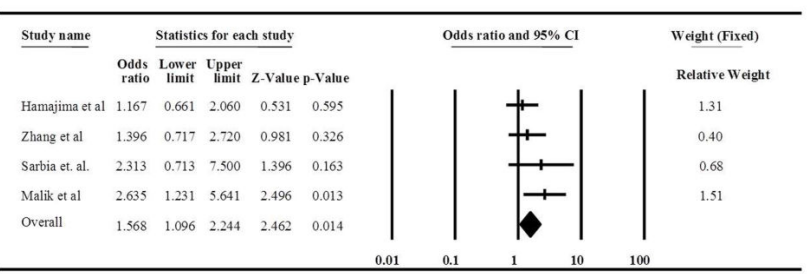

Figure 3: Forest plots of the association between NQO1609C $>\mathrm{T}$ (codominant model; CC vs. TT) polymorphism and GC risk. The random-effects model was used to calculate the pooled effect estimates. The squares and horizontal lines correspond to OR and $95 \%$ CI of specific study, and the area of squares reflects study weight (inverse of the variance). The diamond represents the pooled OR and its $95 \% \mathrm{CI}$.

In subgroup analysis, present study found that $\mathrm{NQO} 1609 \mathrm{C}>\mathrm{T}$ polymorphism was significantly correlated with increased GC risk at allele level ( $\mathrm{OR}=1.302 ; 95 \% \mathrm{CI}=1.111-1.525 ; \mathrm{P}=0.001)$ (Figure 4).

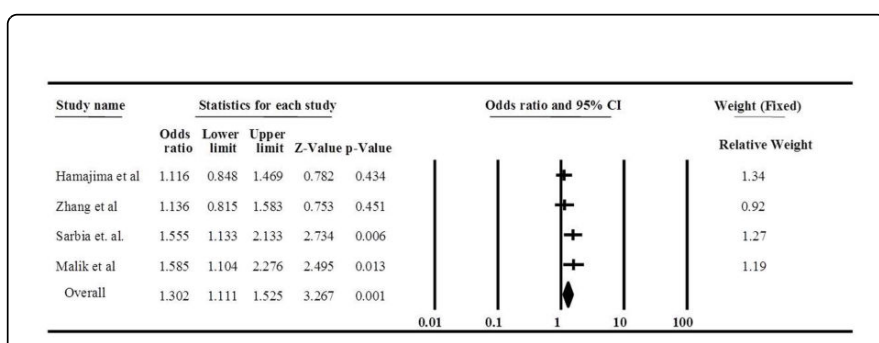

Figure 4: Meta-analysis under allelic model ( $\mathrm{C}$ vs. $\mathrm{T}$ ) for the association between GC risk and the NQO1609C $>$ T polymorphism.

When stratified by dominant and recessive models, significant association was found between NQO1609C $>\mathrm{T}$ polymorphism and risk of $\mathrm{GC}$ in recessive model $(\mathrm{OR}=1.456 ; 95 \% \mathrm{CI}=1.050-2.020 ; \mathrm{P}=0.024)$ but not in dominant $(\mathrm{OR}=1.116 ; 95 \% \mathrm{CI}=0.905-1.376 ; \mathrm{P}=0.030)$ model (Figures 5 and 6). Present study also examined the association between NQO1609C $>$ T polymorphism and GC risk at ethnicity level; the overall result showed that $\mathrm{NQO1609C}>\mathrm{T}$ polymorphism was correlated with GC risk, this association maintained in Asians $(\mathrm{OR}=1.227 ; 95 \% \mathrm{CI}=1.022-1.473 ; \mathrm{P}=0.028)$. 


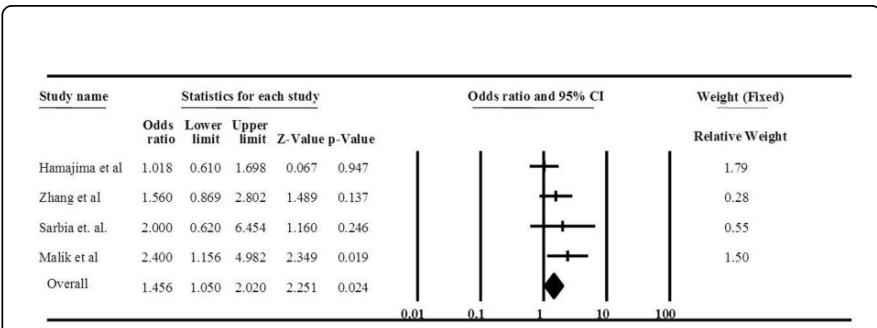

Figure 5: Meta-analysis under recessive model (CC + CT vs. TT) for the association between GC risk and the NQO1609C $>\mathrm{T}$ polymorphism.

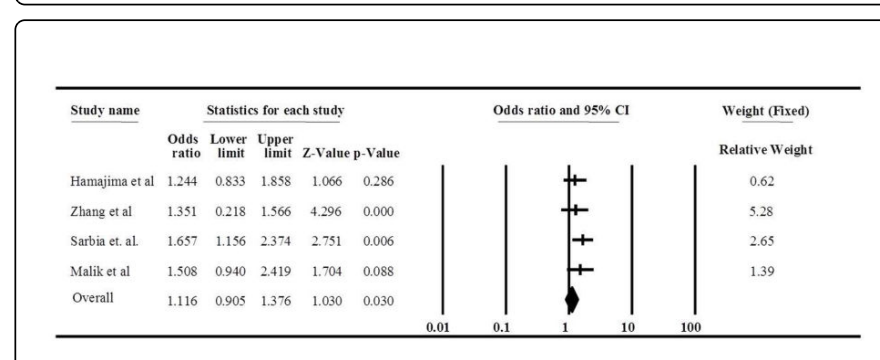

Figure 6: Meta-analysis under dominant model (CC vs. CT+TT) for the association between GC risk and the $\mathrm{NQO} 1609 \mathrm{C}>\mathrm{T}$ polymorphism.

\section{Discussion}

After a comprehensive evaluation of the NQO1 gene C609T polymorphism among 1575 subjects (722 cases and 853 controls), present metaanalysis provided the evidence that the NQO1 609T allele is associated with a significantly increased risk of gastric cancer occurrence, especially in Asians. Although between-study heterogeneity, albeit disturbing, could not be easily eliminated, present results indicated that the NQO1 gene could be a genetic marker for gastric cancer.

The wide geographical variation in the incidence of GC suggests that there are major genetic and environmental influences in the development of this cancer. NQO1 is cytosolic flavoproteins that catalyze the two-electron reduction of quinones and quinoid compounds to hydroquinones, thereby promoting detoxification and preventing the formation of highly reactive oxygen species, which lead to DNA and cell damage [14].

The results of present meta-analysis also suggest that this genetic variant may play a more substantial role in gastric cancer $(\mathrm{OR}=1.568$; $95 \% \mathrm{CI}=1.096-2.244 ; \mathrm{P}=0.014)$. The underlying mechanism of the correlation of NQO1 $609 \mathrm{C}>\mathrm{T}$ polymorphism with increased risk for developing gastric cancer may be related to the different enzyme activities encoded by the different NQO1 genotypes. Thus, lack of NQO1 activity encoded by the homozygous TT genotype results in a reduced detoxification of exogenous carcinogens which causes cells to be easily damaged by oxidation, and thereby increasing the susceptibility to chemically induced cancers. NQO1 null alleles have shown to be associated with other cancers like lymphoblastic leukemia [15] cancer of lung [16] colon [17] breast cancer [18] and colorectal cancer [19]. Chang Gun Cho and coworkers concluded that NQO1
139Arg alleles were associated with tobacco dose-dependent increase in risk of head and neck squamous cell carcinoma, and NQO1 genotype polymorphisms may play an important role in the development of smoking-related HNSCC [20]. However, Hongwei Chen et al. found no relation between NQO1 null allele and lung cancer [21] (Figure 7).

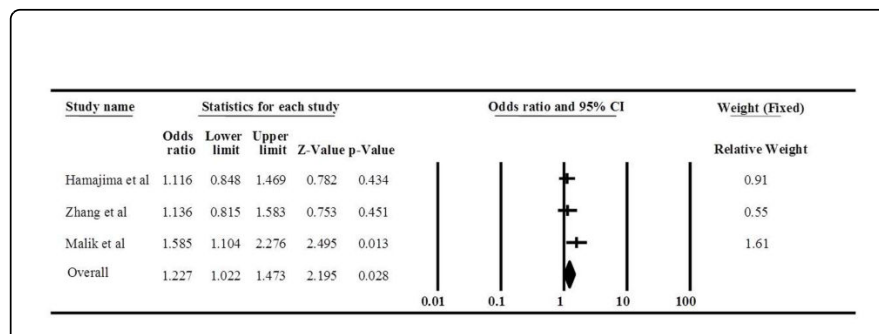

Figure 7: Meta-analysis under ethnicity level for the association between GC risk and the NQO1609C $>$ T polymorphism.

It is well known that NQO1 specifically inihibited by benz-o-pyrine which is a major component of tobacco smoke. The results from NQO1-/- mice suggests that loss of these protein leads to alteration in intracellular redox state and decrease in $\mathrm{p} 53$ protein and apoptosis, which leads to hyperplasia and lymphomas [22,23]. It has also been demonstrated that NQO1 and NQO2 act as endogenous factors in protection against hyperplasia. Individuals carrying both polymorphic genomic alleles are completely lacking in NQO1 activity, whereas individuals who are heterozygous with one polymorphic allele have low-to-intermediate NQO1 activity compared with wild type individuals (5). These findings together raised intriguing questions regarding the susceptibility of NQO1-/- mice and humans deficient in these proteins to develop carcinoma in response to exposures to nitrosamines, radiation and benzene.

A wide variation of the allele frequency has been observed across ethnic groups. The homozygous variant genotype is as rare as $2 \%$ in white populations but as frequent as $20 \%$ in Asian populations [9]. In the present metaanalysis the overall result showed that NQO1609C $>\mathrm{T}$ polymorphism was correlated with GC risk on ethnicity level, this association maintained in Asians $(\mathrm{OR}=1.227$; 95\% $\mathrm{CI}=1.022-1.473$; $\mathrm{P}=0.028)$.

In summary, present study expand previous individual studies on gastric cancer by indicating that the NQO1 C609T polymorphism may increase the risk of GC, especially in Asians. Also, present observations leave open the question regarding the heterogeneous effects of the C609T polymorphism across different ethnic populations. Future studies within a genetic and functional framework are warranted to elucidate the relationship between the C609T polymorphism and gastric cancer, and mechanisms of the NQO1 gene and gastric cancer.

\section{Acknowledgment}

We sincerely acknowledge the financial support of Department of Biotechnology, Government of India (Grant No. BT/PR7270/MED/ 30/909/2012). 
Citation: Malik MA, Haq S, Yetoo DM, Malik SA, Shah ZA (2016) NADPH: Quinone oxidoreductase 1 (NQO1609C>T) Polymorphism and Gastric Cancer Risk: A Meta-Analysis. J Carcinog Mutagene 7: 249. doi:10.4172/2157-2518.1000249

Page 5 of 5

\section{References}

1. Bray F, Jemal A, Grey N, Ferlay J, Forman D (2012) Global cancer transitions according to the Human Development Index (2008-2030): a population-based study. The lancet oncology 13: 790-801.

2. Gonzalez CA, Sala N, Capella G (2002) Genetic susceptibility and gastric cancer risk. Int J Cancer 100: 249-260.

3. Jaiswal AK (2004) Nrf2 signaling in coordinated activation of antioxidant gene expression. Free Radic Biol Med 36: 1199-1207.

4. Traver RD, Siegel D, Beall HD, Phillips RM, Gibson NW, et al. (1997) Characterization of a polymorphism in $\mathrm{NAD}(\mathrm{P}) \mathrm{H}$ : quinone oxidoreductase (DT-diaphorase). Br J Cancer 75: 69-75.

5. Siegel D, McGuinness SM, Winski SL, Ross D (1999) Genotypephenotype relationships in studies of a polymorphism in $\mathrm{NAD}(\mathrm{P}) \mathrm{H}$ :quinone oxidoreductase 1. Pharmacogenetics 9: 113-121.

6. Misra V, Grondin A, Klamut HJ, Rauth AM (2000) Assessment of the relationship between genotypic status of a DT-diaphorase point mutation and enzymatic activity. Br J Cancer 83: 998-1002.

7. Kuehl BL, Paterson JW, Peacock JW, Paterson MC, Rauth AM (1995) Presence of a heterozygous substitution and its relationship to DTdiaphorase activity. Br J Cancer 72: 555-561.

8. Nebert DW, Roe AL, Vandale SE, Bingham E, Oakley GG (2002) $\mathrm{NAD}(\mathrm{P}) \mathrm{H}$ :quinone oxidoreductase (NQO1) polymorphism, exposure to benzene, and predisposition to disease: aHuGE review. Genet Med 4: 62-70.

9. Kelsey KT, Ross D, Traver RD, Christiani DC, Zuo ZF, et al. (1997) Ethnic variation in the prevalence of a common $\mathrm{NAD}(\mathrm{P}) \mathrm{H}$ quinone oxidoreductase polymorphism and its implications for anti-cancer chemotherapy. Br J Cancer 76: 852-854.

10. Hamajima N, Naito M, Kondo T, Goto Y (2006) Genetic factors involved in the development of Helicobacter pylori-related gastric cancer. Cancer Sci 97: 1129-1138.

11. Zhang JH, Li Y, Wang R, Geddert H, Guo W, et al. (2003) NQO1 C609T polymorphism associated with esophageal cancer and gastric cardiac carcinoma in North China. World J Gastroenterol 9: 1390-1393.

12. Sarbia M, Bitzer M, Siegel D, Ross D, Schulz WA, et al. (2003) Association between $\mathrm{NAD}(\mathrm{P}) \mathrm{H}$ : quinone oxidoreductase 1 (NQ01) inactivating C609T polymorphism and adenocarcinoma of the upper gastrointestinal tract. Int J Cancer 107: 381-386.
13. Malik MA, Zargar SA, Mittal B (2011) Role of NQO1 609C\&gt; T and NQO2-3423G\&gt;A polymorphisms in susceptibility to gastric cancer in Kashmir valley. DNA Cell Biol 30: 297-303.

14. Strassburg A, Strassburg CP, Manns MP, Tukey RH (2002) Differential gene expression of $\mathrm{NAD}(\mathrm{P}) \mathrm{H}$ :quinone oxidoreductase and $\mathrm{NRH}$ :quinone oxidoreductase in human hepatocellular and biliary tissue. Mol Pharmacol 61: 320-325.

15. Li C, Zhou Y (2014) Association between NQO1 C609T polymorphism and acute lymphoblastic leukemia risk: evidence from an updated metaanalysis based on 17 case-control studies. J Cancer Res Clin Oncol 140: 873-881.

16. Kiyohara C, Yoshimasu K, Takayama K, Nakanishi Y (2005) NQO1, MPO, and the risk of lung cancer: A Huge review. Genet Med 7: 463-478.

17. Begleiter A, Hewitt D, Maksymiuk AW, Ross DA, Bird RP (2006) A NAD (P) H: Quinone Oxidoreductase 1 Polymorphism Is a Risk Factor for Human Colon Cancer. Cancer Epidemiol Biomarkers Prev 15: 2422-2426.

18. Fowke JH, Shu XO, Dai Q, Jin F, Cai Q, et al. (2004) Oral Contraceptive Use and Breast Cancer Risk: Modification by NAD (P) H: Quinone Oxoreductase (NQO1) Genetic Polymorphisms. Cancer Epidemiol Biomarkers Prev 13: 1308-1315.

19. Zhao ZQ, Guan QK, Yang FY, Zhao P, Zhou B, et al. (2012) System review and metaanalysis of the relationships between five metabolic gene polymorphisms and colorectal adenoma risk. Tumour Biol 33: 523-535.

20. Cho CG, Lee SK, Nam SY, Lee MS, Lee SW, et al. (2006) Association of the GSTP1 and NQO1Polymorphisms and Head and Neck Squamous Cell Carcinoma Risk. J Korean Med Sci 21: 1075-1079.

21. Chen H, Lum A, Seifried A, Wilkens LR, Le Marchand L (1999) Association of the NAD (P) H: Quinone Oxidoreductase 609C3T Polymorphism with a Decreased Lung Cancer Risk. Cancer Res 59: 3045-3048.

22. Iskander K, Jaiswal AK (2005) Quinone oxidoreductases in protection against myelogenous hyperplasia and benzene toxicity. Chem Biol Interact 153-154: 147-157.

23. Iskander K, Barrios RJ, Jaiswal AK (2009) NRH:quinone oxidoreductase 2-deficient mice are highly susceptible to radiation-induced B-cell lymphomas. Clin Cancer Res 15: 1534-1542. 